\title{
TOWARD JUST AND SUSTAINABLE CITIES: IDENTIFYING KEY AREAS FOR URBAN, PERI-URBAN AND RURAL SUSTAINABILITY COLLABORATIVE INITIATIVES
}

\author{
ERIC CHAPMAN ${ }^{1}$, LAUREN ROGERS $^{1} \&$ ADAM KAY $^{1}$ \\ ${ }^{1}$ Department of Biology, University of Saint Thomas, USA
}

\begin{abstract}
Increasing urbanization and changing population demographics represent two golden opportunities to reimagine how humanity may influence the trajectory of the planet. Although there is substantial information about 'the speed in which we are falling off the cliff' with respect to the negative effects of climate change, biodiversity loss, and nitrogen and phosphorus overuse, much less is known about how humanity may transition to living within sustainable ecological and social boundaries. Transitioning to global sustainability requires a framework that integrates both fundamental ecological boundaries with social foundations that provide basic needs. One such framework is Raworth's Doughnut Model, where the doughnut indicates a 'sweet spot': meeting basic social needs of all within sustainable boundaries for earth-systems processes. While there are a global and a few national level analyses of sustainability using this framework, there are no regional level assessments. We used Raworth's Doughnut Model to assess regional level sustainability for a mid-sized metropolitan area in the Midwestern United States. We pooled county data from government and non-profit reports to quantify social foundation and ecological boundary sustainability across one of the most populous regions in the upper Midwestern United States. Our regional doughnut analysis revealed many ecological overshoots and social deficits, and identified key areas for urban, peri-urban and rural sustainability collaborations. Our analysis also revealed the importance of geospatial variation in ecological boundary overshoot and social deficits. In many ways, our study system of the upper Midwestern United States is representative of city sizes of the future and understanding these trajectories of ecological and social parameters may inform future global sustainable pathways.

Keywords: doughnut economics, peri-urban, rural, urban, urban sustainability.
\end{abstract}

\section{INTRODUCTION}

Humans have fundamentally transformed the global environment. Current human impacts on earth-system processes include biogeochemical cycling (including carbon [1], nitrogen [2] and phosphorus cycles [3]), biodiversity loss [4], and land use and cover change [5]. All of these impacts are occurring at rates and scales that are orders of magnitudes greater than pre-industrial levels. In the short term, at least some of these ecological transformations have improved (albeit unevenly) human well-being and longevity by increasing the availability of food, shelter and potable water. However, the extent of human impacts on many earth system processes are widely viewed as being unsustainable as they either currently overshoot or are set to overshoot 'planetary boundaries' for these processes estimated by leading researchers [6], [7] . As a result, the long-term value of the social benefits gained from human activities can only be assessed by also determining their impact on the global environment.

A new conceptual framework, the Doughnut Model (DM), has emerged to simultaneously evaluate social gains and environmental impacts of human activities [8]. The DM consists of an outer ring that represents an 'ecological ceiling' of planetary boundaries (estimated in a previous study [6] for nine earth-system processes, including climate change, biodiversity loss, and nitrogen and phosphorus cycling), and an inner 'social foundation' ring, which are estimated minimum levels for various social metrics (including food access, housing and jobs) needed for all humans to thrive. The area between the ecological ceiling and social 
foundation, the 'meat' of the doughnut, represents the safe and just space for humanity in which basic human social needs are met without overshooting impacts on critical earth systems. This approach, applied at global and national scales, has helped to identify key tradeoffs associated with increasing broad levels of economic activities in order to meet general social goals.

Here, we modify the DM to explore its relevance for assessing the concept of sustainability and urban and regional scales (Fig. 1). We envision a framework in which 'boundaries' for earth-system processes can be estimated at finer scales such that ecological ceilings can be determined for cities and surrounding areas. At the same time, we suggest that 'social foundations' can be determined for regions depending on global standards that may or may not reflect existing conditions. We do not currently have the capacity to estimate ecological ceilings or social foundations at the regional scale, but we seek to illustrate the potential for this approach by contrasting environmental and social impacts in a targeted area.

The focus on cities and surrounding regions is important given how urbanization and changing population demographics are increasingly impacting the trajectory of the planet. In 2007, for the first time ever, the majority of humans lived in cities [9]. As more people move to cities and cities expand, transportation infrastructure can provide mobility for more people, more efficiently and with lower carbon emissions [10]. Urbanization introduces resource efficiencies provided by higher densities of people and represents an opportunity

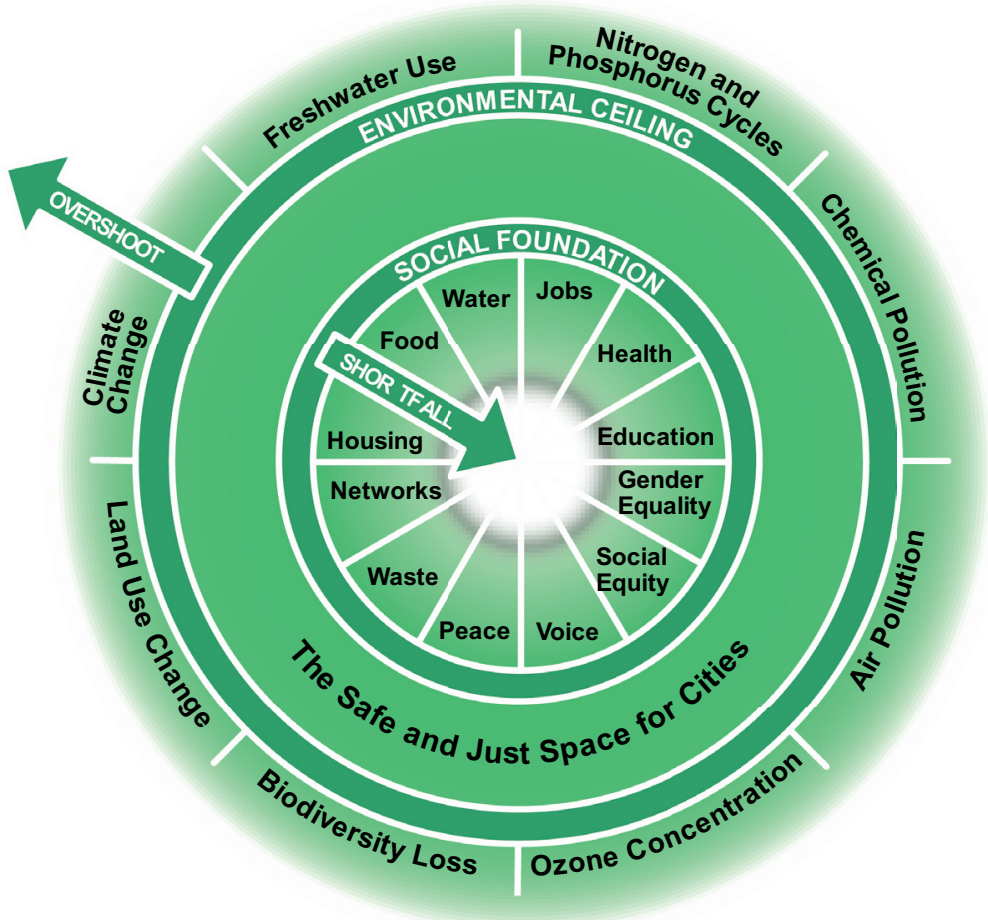

Figure 1: Doughnut Model consisting of an ecological ceiling outer ring and social foundation inner ring. The space between the rings represents the safe and just space for cities. Adapted and modified from [8]. 
to increase urban sustainability [11]. Although cities can provide resource efficiency from density, cities heavily rely on material and energy exchange with local, regional and national systems as well as the broader global system [12].

In this study, we compiled and compared modified ecological ceiling excesses and social foundation deficits from the urban, peri-urban and rural counties surrounding a populous urban centre (Minneapolis-St. Paul, MN) in the Upper Midwest region of the United States. Our goal is to estimate the extent to which different regions can be considered 'sustainable' when environmental and social factors are considered simultaneously and to suggest how sustainability could be enhanced at the regional level by identifying key areas for collaborative initiatives among urban, peri-urban and more rural communities.

\section{METHODS}

\subsection{Study system}

The Upper Midwestern United States is a heterogenous landscape consisting of diverse land uses across multiple states. The region is largely agricultural, though it contains numerous relatively densely populated urban and suburban areas $\left(>300\right.$ people $\left.\mathrm{km}^{-2}\right)$, moderately dense peri-urban areas (between 100-282 people $\mathrm{km}^{-2}$ ) and low-density rural areas $(<100$ people $\mathrm{km}^{-2}$; Fig. 2). In this study, we focused on one of the most populated regions of the Upper Midwestern United States, which is anchored by the Twin Cities of Minneapolis and St. Paul located in Minnesota (MN; 2010 population 3.28 million people).

\subsection{Study approach and data collection}

To create preliminary regional sustainability estimates, we applied Raworth sustainability metrics using a county-level perspective. We used this approach to investigate the influence of county-level policy on sustainability outcomes and to assess to what extent county-level

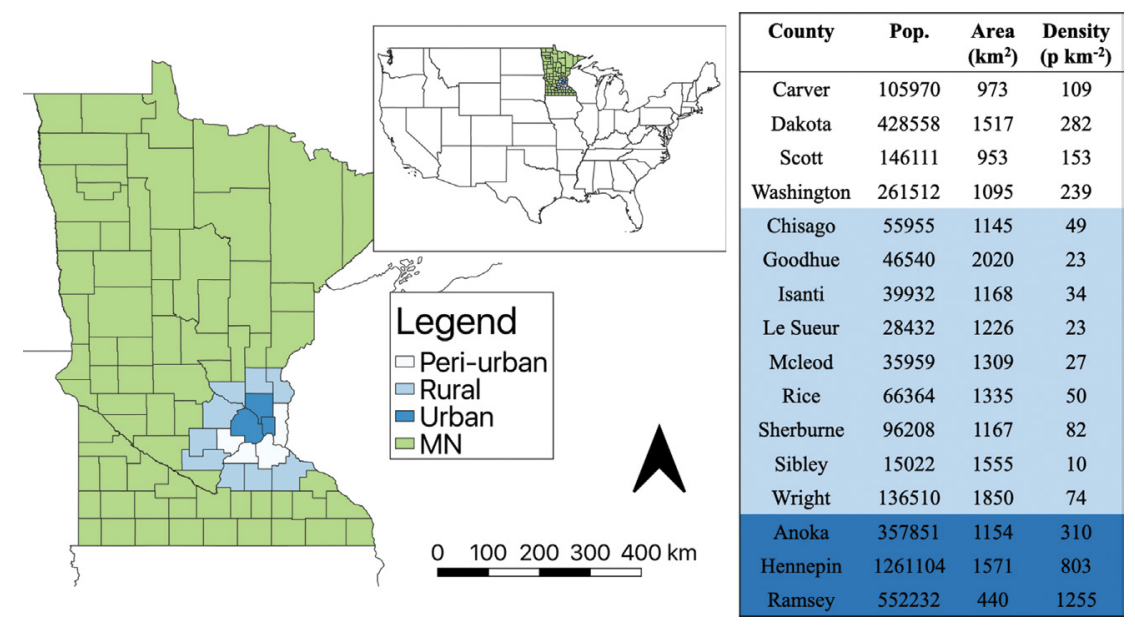

Figure 2: Study area of the metropolitan counties surrounding the Twin Cities of Minneapolis and St. Paul in Minnesota (MN; left panel) and key information for each of the counties (right panel). Dark blue counties are urban, light blue counties are rural and counties in white are peri-urban. 
policy may drive regional sustainability efforts. Additionally, data from the county level were more available compared to other levels such as at the city level. For the sake of our analysis, we classified county types (urban, peri-urban and rural) based on the population densities mentioned above.

To assess regional sustainability within our study system, we collected a variety of social and ecological parameters inspired by previous studies [8], [13]. We modified these parameters for each slice of the 'doughnut' to better reflect social and ecological conditions that are relevant for estimating sustainability at the regional scale around a city in the developed world. For example, we did not include 'ocean acidification' as a relevant earth-system process because of the geographic location of our region of study. Similarly, we made several changes to social foundation metrics used in [8] to make them more relevant to social challenges in this region. Our modifications are discussed in more detail in 2.2.1.

We collected and compiled data from various state agencies including the Minnesota (MN) Department of Health, MN Board of Soil and Water Resources, MN Pollution Control Agency, MN Department of Agriculture, MN Employment and Economic Development, MN Secretary of State, MN State Demographic Center and the MN Legislature Legislative Coordinating Commission. Beyond state agency data, we collected and compiled data from national agencies including the U.S. Geological Survey, U.S. Census Bureau, National Center for Health Statistics and the Center for Disease Control. Finally, we also compiled data from various non-profit organizations (Table 1).

\subsubsection{Ecological ceiling and social foundations metrics}

To investigate how ecological and social factors varied between county types in a developed world context, we modified the global ecological and social foundation parameters defined by Raworth (Table 1). We selected metrics based on data availability to better reflect living conditions in the Upper Midwestern United States. In areas where global ecological ceilings are not defined by Raworth, we developed county-level methodology to assess regional contributions to ecological ceiling overshoot. For example, a global ecological ceiling for both air and chemical pollution has not been established, but at the county level, robust datasets exist for particulate matter less than 2.5 microns in size (PM 2.5), a measure of local air pollution. For metrics where established ecological ceilings exist, but county-level data were absent, we developed alternative proxies for the established ecological ceiling metric. For example, we used $\mathrm{NO}_{\mathrm{x}}$ emissions as a proxy for regional contributions to the climate change ecological ceiling; no county-level $\mathrm{CO}_{2}$ emissions data were available. For a comprehensive list of the metrics we modified for this county-level analysis, see Table 1. To express social foundation metrics consistently as deficits, we manipulated several parameters that were not originally expressed as deficits (e.g. health as life expectancy). The following metrics were modified: health, education, political voice, gender equality, networks and work. We expressed 1) life expectancy deficits in our study region compared to the top ten life expectancy industrialized countries (mean 83.3 years); 2) education as a percent of those not attaining bachelor's degrees; 3) political voice as non-voter turnout; 4) gender equality as deficit from $50 \%$ female representation in local government and 5) work as an income deficit compared to the mean income in the state of Minnesota. Justifications and implications of these modifications are further described in our Discussion. 
Table 1: Metrics for assessing sustainability using the Doughnut Model.

\begin{tabular}{|c|c|c|c|}
\hline $\begin{array}{l}\text { Sustainability } \\
\text { Category }\end{array}$ & Raworth Metric (Units) & Modified Metric (Units) & Reference \\
\hline \multicolumn{4}{|l|}{ Ecological ceiling } \\
\hline Climate change & $\mathrm{CO}_{2}(\mathrm{ppm})$ & $\mathrm{NO}_{\mathrm{x}}\left(\mathrm{kg} \mathrm{y}^{-1}\right)$ & {$[14]$} \\
\hline Ocean acidification & Aragonite saturation & Not applicable & \\
\hline Chemical pollution & Not defined & Not defined & \\
\hline $\mathrm{N}$ and $\mathrm{P}$ cycles & Fertilizer use (tons $\mathrm{y}^{-1}$ ) & Fertilizer use $\left(\mathrm{kg} \mathrm{y}^{-1} \mathrm{~km}^{-2}\right)$ & {$[15]$} \\
\hline $\begin{array}{l}\text { Freshwater } \\
\text { withdrawals }\end{array}$ & $\mathrm{H}_{2} \mathrm{O}$ use $\left(\mathrm{km}^{3} \mathrm{y}^{-1}\right)$ & $\mathrm{H}_{2} \mathrm{O}$ use per capita $\left(\mathrm{m}^{3} \mathrm{y}^{-1}\right)$ & {$[16]$} \\
\hline Land conversion & $\begin{array}{l}\text { Forested land prior to } \\
\text { alteration }(\%)\end{array}$ & Not defined & \\
\hline Biodiversity loss & Species extinction $\left(\operatorname{spp} \mathrm{y}^{-1}\right)$ & Land not conserved (\%) & {$[17]$} \\
\hline Air pollution & Not defined & PM $2.5\left(\mu \mathrm{g} \mathrm{m}^{-3}\right)$ & {$[18]$} \\
\hline $\begin{array}{l}\text { Ozone layer } \\
\text { depletion }\end{array}$ & $\mathrm{O}_{3}(\mathrm{DU})$ & $\mathrm{O}_{3}\left(\mu \mathrm{g} \mathrm{m}^{-3}\right)$ & {$[19]$} \\
\hline \multicolumn{4}{|l|}{ Social foundations } \\
\hline Food & Undernourished (\%) & Food insecurity (\%) & {$[20]$} \\
\hline Health & $\begin{array}{l}\text { Life expectancy/under } 5 \\
\text { mortality }(\mathrm{y} / \%)\end{array}$ & $\begin{array}{l}\text { Life expectancy compared } \\
\text { to } 10 \text { highest in world }(y)\end{array}$ & {$[21]$} \\
\hline Education & Literacy/dropout (\%) & $\%$ Without bachelors & {$[22]$} \\
\hline Jobs & $\begin{array}{l}\text { Population below interna- } \\
\text { tional poverty limit }(\%)\end{array}$ & $\begin{array}{l}\text { Annual income relative to } \\
\text { MN mean (per capita) }\end{array}$ & {$[23]$} \\
\hline Peace/justice & $\begin{array}{l}\text { Homicide rate; corruption } \\
\text { index }(\%)\end{array}$ & Homicide rate $(\# / 100,00)$ & {$[24]$} \\
\hline Political voice & Voter accountability index & Voter non-turnout $(\%)$ & {$[25]$} \\
\hline Social equity & Palma ratio & Gini index & {$[26]$} \\
\hline Gender equality & $\begin{array}{l}\text { Political representation; } \\
\text { pay gap }\end{array}$ & $\begin{array}{l}\text { Deficit to } 50 \% \text { female } \\
\text { representation }\end{array}$ & [27] \\
\hline Housing & Slum housing (\%) & Homeless (\#) & [28] \\
\hline Networks & Without internet access $(\%)$ & $\begin{array}{l}\% \text { Without broadband } \\
\text { internet }\end{array}$ & [29] \\
\hline $\begin{array}{l}\text { Energy/waste } \\
\text { management }\end{array}$ & $\begin{array}{l}\text { Lacking access to } \\
\text { electricity }(\%)\end{array}$ & Landfill waste $\left(\mathrm{kg} \mathrm{y}^{-1}\right)$ & {$[30]$} \\
\hline Water & $\begin{array}{l}\text { Lacking access to sanita- } \\
\text { tion and water }(\%)\end{array}$ & $\mathrm{NO}_{3}^{-}\left(\mathrm{mg} \mathrm{m}^{-3}\right)$ & {$[31]$} \\
\hline
\end{tabular}




\subsection{Statistical analyses}

To measure whether or not there were differences in the county-level ecological ceiling and social foundation metrics from Raworth (Table 1), we used multiple one-way ANOVA statistical tests in R. We assessed the linearity, normality and equal variance assumptions of the statistical tests using $\mathrm{R}$ and we assumed that our data were independent. We plotted our data in R to measure linearity, and we tested the normality and equal variance assumptions visualizing Normal Q-Q and Residuals versus Fitted plots, respectively, in R. Where we found group means that were significantly different $(P<0.05)$, we performed Tukey's post-hoc analyses. In cases where assumptions of the statistical tests were violated, we either logtransformed the data and performed parametric analyses or used non-parametric ANOVAs on non-transformed data. In Fig. 3, we depicted groups that were significantly different from one another using different letters.

\section{RESULTS}

\subsection{Regional and county demographics}

In 2019 , the population of the 16-county study site was 3,634,260 and the mean county population was 227,141 . Total and mean population sizes varied by county type: the total population of urban counties $(n=4)$ was 2,599,745 and the mean population size for urban counties was 649,936; the total population size of peri-urban counties $(n=3)$ was 513,593 and the mean of peri urban counties was 171,197; the total population of rural counties $(n=9)$ was 520,922 and the mean population size for rural counties was 57,880 .

The mean population density of counties significantly decreased from urban to rural classified counties $(P<0.001)$ and peri-urban counties had an intermediate population density. Urban county population density was $663 \pm 238$ people $\mathrm{km}^{-2}$ (mean \pm SE), peri-urban was $167 \pm 33$ people $\mathrm{km}^{-2}$ and rural was $41 \pm 9$ people $\mathrm{km}^{-2}$. County areal size did not differ between urban, peri urban and rural counties $(P=0.241)$.

\subsection{Ecological ceiling}

Along the urban core to rural county gradient, we found differences in the suite of the ecological ceiling metrics of sustainability. Metrics for climate change $\left(\mathrm{NO}_{\mathrm{x}}\right)$, nitrogen $(\mathrm{N})$ cycling, air pollution (PM 2.5) and ozone concentration all varied along our study gradient. Freshwater withdrawals, phosphorus cycling and biodiversity loss did not vary along the county gradient.

We found that urban counties had significantly higher measures for climate change and air pollution and significantly lower measures for ozone concentration compared to rural counties. $\mathrm{N}$ and $\mathrm{P}$ cycling in urban farms was significantly lower on a per unit area compared to rural farm $\mathrm{N}$ loading. Non-farm $\mathrm{N}$ and $\mathrm{P}$ cycling was significantly higher in urban counties compared to rural and peri-urban counties. Total $\mathrm{N}$ cycling was higher in rural counties compared to urban counties (Figure 3). However, total P cycling (farm and non-farm combined) did not vary across county type in our study area. Peri-urban counties had similar measures of climate change and $\mathrm{N}$ and $\mathrm{P}$ cycling compared to both urban and rural counties; peri-urban counties had intermittent measures of climate change and $\mathrm{N}$ and $\mathrm{P}$ cycling compared to both urban and rural counties. Rural counties had the lowest measures of climate change and air pollution, but also the highest metrics for ozone depletion and $\mathrm{N}$ cycling. 

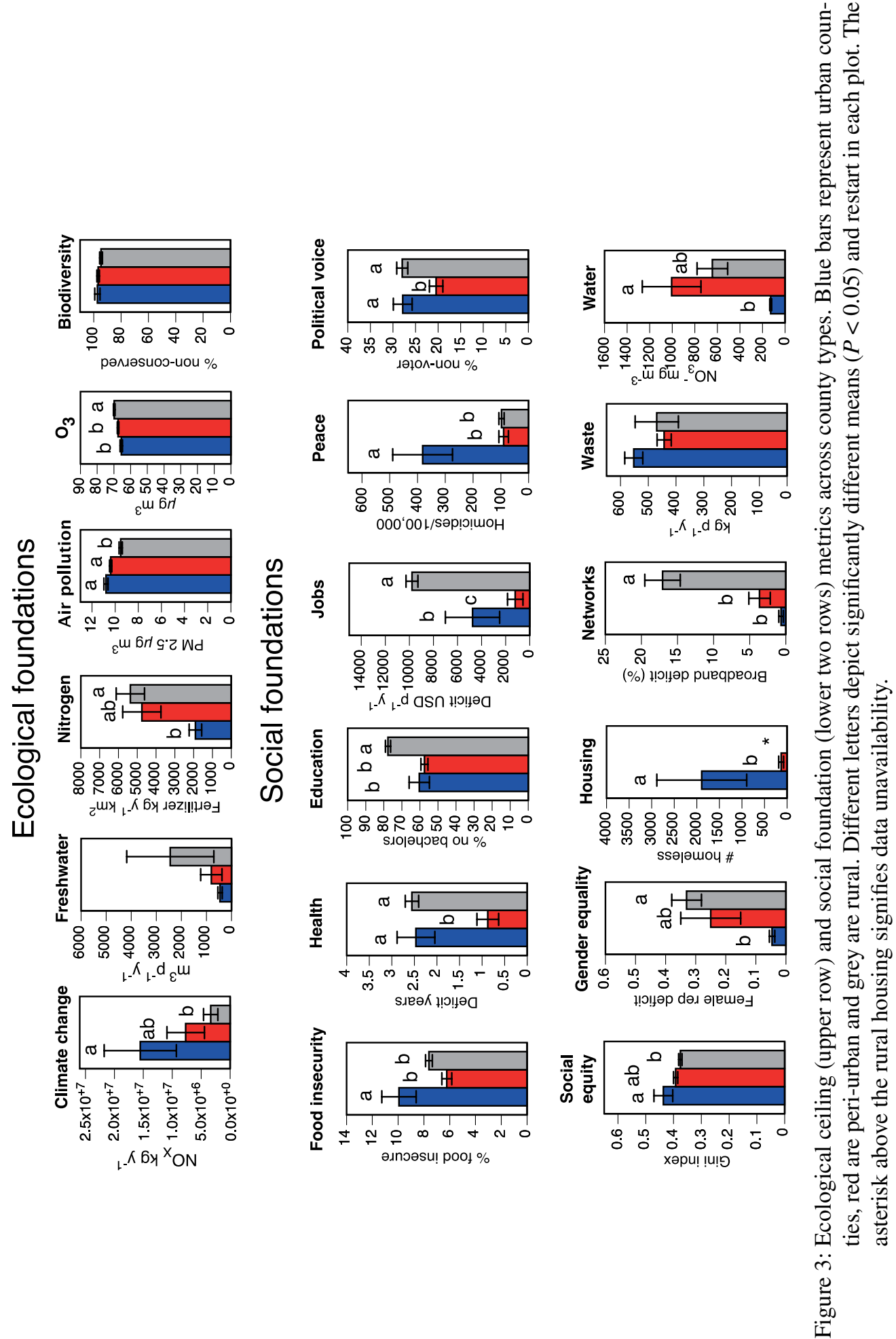


\subsection{Social foundations}

Along the urban core to rural county gradient we found differences in a suite of the social foundation metrics of sustainability; the only metrics that did not vary were metrics for waste management. We found differences in rates of food insecurity, life expectancy, levels of educational attainment, per capita income, homicide rate, voter non-turnout, Gini index, deficit in equal female representation in local government, homeless population size, access to broadband internet and water quality across urban, peri-urban and rural regions in our study system (Fig. 3).

Several social metrics showed highest deficits in urban areas. The most striking differences in deficits in peace (homicide rates $\sim 4 \times$ higher in urban counties than in other counties) and housing (homeless rates $\sim 10 \times$ higher in urban counties). Other particularly high deficits in urban counties were in food access and social equity. Deficits for health and political voice were similarly higher in urban and rural areas than in peri-urban areas.

Some deficits were significantly lower in urban counties than other regions. These deficits include water quality and gender equality (higher quality and more equitable gender representation in urban areas than in other areas). Education deficits were lower in both urban and peri-urban areas compared to rural areas. Peri-urban areas had particularly low-income deficits compared to urban areas, which in turn were significantly lower than rural counties.

\section{DISCUSSION}

Overall, our results suggest that environmental overshoots and social deficits show contrasting patterns in urban, peri-urban and rural counties. As a result, none of the three regions is clearly 'more sustainable' than the other two. However, the contrasting patterns suggest that collaboration and exchange among regions could contribute to a broader regional sustainability. We also illustrate how the DM approach can start a more transdisciplinary discussion in which environmental and social impacts are considered in a common framework.

\subsection{Patterns in key social and environmental metrics}

Our results show that many social and environmental metrics differ among urban, peri-urban and rural areas. Generally, we found that rural counties lacked access to necessary 21st century infrastructure (broadband internet) and attributes (bachelor's degrees) but had more social equity (Gini index was lower), and urban counties had higher pollution, homelessness, homicide, gender equity and food insecurity.

Interestingly, our measure for biodiversity loss (percent of land not enrolled in conservation programs) was low ( $>94.5 \%$ of total land area) and did not vary along our study gradient. Our measure only included land explicitly enrolled in conservation programmes at the federal and state level and did not include other areas of potential high biodiversity such as county or city parks (see [32]). The percentage of land enrolled in state and federal conservation programmes across our study area was below the statewide percentage of $6.6 \%$. This relatively low percentage of conservation land suggests that land in the Twin Cities metro is used for housing in urban counties and food production in rural counties in similar quantities, given variation in population density along this gradient. Another interesting finding was that per capita waste generation/percentage of non-landfill waste and freshwater withdrawal rates did not vary along our study gradient. The lack of variation along our study gradient contradicts a previous study that quantified rates of recycling and stewardship participation [33]. That study found higher rates of recycling participation in rural areas compared to urban areas. 
There were several metrics that showed substantial differences across our study system. Along the rural to urban county continuum, there are numerous different uses for freshwater withdrawals. Within our study area, freshwater withdrawals are used for crop irrigation, public water supply, industrial water use, golf course irrigation, water for cattle and nuclear power production. In the United States, thermoelectric power generation is one of the biggest consumers of freshwater withdrawals; in 2005, thermoelectric power stations accounted for $41 \%$ of the nation's freshwater withdrawals [34]. Given that our study area houses two thermoelectric power generating stations that draw freshwater from multiple different county types, it is not surprising that we found large variation between and within county types. Of the nine rural counties in this study, six counties supplied thermoelectric power generating stations with freshwater withdrawals. Additionally, two of the three urban counties and two of the four peri-urban counties supplied thermoelectric power generating stations with freshwater withdrawals. This variation was driven by large freshwater withdrawals where thermoelectric power generating stations were and non-existent withdrawals where they were not located.

We also observed large variation of $\mathrm{N}$ and $\mathrm{P}$ cycling in our study area. This pattern was driven by within county type variation in $\mathrm{N}$ and $\mathrm{P}$ fertilizer application and suggests that county lines are not the best predictor of fertilizer intensive agricultural activities. Additionally, there are a few counties in our study area in the peri-urban fringe where housing increases near the urban core as low-density suburban housing. Although we observed large variation of $\mathrm{N}$ and $\mathrm{P}$ cycling within counties and differences between non-farm and farm $\mathrm{N}$ and $\mathrm{P}$ inputs, there was no difference in total $\mathrm{P}$ cycling between county types. This suggests that urban and peri-urban commercial application of $\mathrm{P}$ fertilizers in non-farm settings is similar to fertilizer application in farm settings in rural areas.

\subsection{Limitations to the current approach and possible next steps}

The DM provides an approach for quantifying the extent to which human activities transgress boundaries around 'a safe and just' operating space for humanity. This approach is valuable because boundaries can represent scientific targets that can galvanize large-scale and coordinated efforts to transform social and economic systems. Although much progress has been made in applying this approach to global issues, it remains a challenge to use a similar approach to the regional scales that are the focus of most policy initiatives.

One major constraint for applying the DM to a regional scale is the lack of recognized regional boundaries for earth system processes. For example, $350 \mathrm{ppm}$ for $\mathrm{CO}_{2}$ concentration has been proposed as an appropriate planetary boundary for human climate change impacts given predicted impacts of greenhouse gas levels on future warming. However, we did not have the capacity in our current study to try to convert this and similar global planetary estimates to per-capita estimates that could be applied to make regional boundary estimates.

Another constraint for creating a regional DM is the lack of accepted measures for what should constitute a 'social foundation'. For example, Raworth uses a global social foundation for 'health' as the 'percentage of countries with life expectancy less than 70 years'. It is unclear if this same metric should be used to assess health in counties in a developed country like the United States. In one sense, it could be argued that the average life expectancy in our sample (78 years) exceeds global social foundation levels. However, it is also true that life expectancy in the United States is significantly lower than many other developed countries and that a standard of 70 years is far lower than what should be possible in a developed setting. Determining appropriate social foundation metrics for regions should be a top priority for policy makers moving forward. 


\subsection{Potential key areas for urban-peri-urban-rural sustainability collaborations}

Urban regions require key resources far beyond their geographic boundaries. This broad reliance across spatial scales implies that one way to increase city and urban sustainability is to increase regional sustainability. Increasing regional sustainability will require a profound shift in how humanity thinks about energy, food systems and transportation networks. Efficiencies in critical infrastructure (sanitation system and water treatment facilities), transportation - trains, subways and bus routes - systems and utility service delivery are a few of the reasons cities are frequently cited as essential elements in achieving global sustainability. In other words, it is more cost-effective and less resource intensive to provide services such as municipal water, sewer and electric delivery in more dense urban centres compared to rural areas. Despite these efficiencies, cities are necessarily large importers of resources far from their geographical boundaries [12]. This apparent paradox-cities offer both a sustainable vision for efficient resource use and an immense scale of consumption-highlights the importance of sustainable regional planning and coordination. If we think beyond the traditional planning boundaries, can we design regions that maximize social foundations outcomes while minimizing ecological ceiling overshoot? Urban counties in metropolitan areas will continue to be net resource importers; there are several areas where urban, peri-urban and rural counties could better collaborate to increase sustainability.

Through this analysis, we quantified how urban, peri-urban and rural counties compared across ecological ceiling and social foundation metrics using the DM. Given the patterns in social foundation and ecological ceiling metrics we found, it appears there could be several areas that urban, peri-urban and rural counties could collaborate to increase the regional sustainability of our study area. One potential area to increase regional sustainability across county types is with $\mathrm{N}$ and $\mathrm{P}$ cycling. In 2005, Minnesota banned the application of P fertilizer on lawns and turfgrass in most cases. Banning the sale of fertilizer containing P reduced the concentrations of $\mathrm{P}$ in surface waters [35]. Perhaps this same model could be used to discourage excessive $\mathrm{N}$ fertilizer inputs on the landscape. Decreasing the mass of $\mathrm{N}$ and $\mathrm{P}$ fertilizer used in the non-agricultural context could decrease regional nutrient inputs and the ecological ceiling overshoot of this boundary while not jeopardizing food production in agricultural contexts.

Another way to decrease ecological ceiling metrics (climate change, air pollution and ozone depletion) is to increase regional transportation networks. The production of NOx and PM 2.5, and the depletion of ozone are all tied to industrial and fossil fuel burning activities. Furthermore, the production of NOx can deplete ozone, increasing risks for solar UV damage [36]. Expanding regional transportation networks such as light rail can increase urban sustainability and resiliency by decreasing reliance on fossil fuel combustion [37]. Increasingly, planners, urban designers, scientists and community members are co-producing visions for sustainable regional planning. In our study area, the Metropolitan Council-a regional planning agency-owns and operates the Metro Transit Authority, a vital element of regional transportation, and multiple wastewater treatment facilities. This regional planning perspective is uncommon in the United States and represents one potential model to foster regional collaboration to increase sustainability. Beyond decreasing the ecological ceiling metrics (climate change, air pollution and ozone concentration), an expanded regional transportation network could increase various social foundation metrics. Transportation networks to urban areas increase educational opportunities and accessibility of higher income jobs, and provide better access to healthcare facilities [38], [39], [40]. 
While it is thermodynamic law that some system waste and inefficiency is inevitable, collaboration on sustainability initiatives among urban, peri-urban and rural counties could decrease this waste and inefficiencies and increase social foundations and broader regional sustainability. More coordination and collaboration between county types to address ecological ceiling overshoot and social foundation deficits could improve well-being while reducing ecological ceiling overshoot.

\section{ACKNOWLEDGEMENTS}

We thank John Schade for influential conversations about sustainability and the Doughnut Model, which greatly informed our approach in this article; the University of St. Thomas for institutional and financial support; and Kenna Kay for graphic design support.

\section{REFERENCES}

[1] P. M. Vitousek, H. A. Mooney, J. Lubchenco, J. M. Melillo, Human domination of Earth's ecosystems. Science 277, 494-499 (1997).

[2] P. M. Vitousek, et al., Human alteration of the global nitrogen cycle: sources and consequences. Ecological Applications 7, 737-750 (1997).

[3] D. L. Childers, J. Corman, M. Edwards, J. J. Elser, Sustainability challenges of phosphorus and food: solutions from closing the human phosphorus cycle. BioScience 61 , 117-124 (2011).

[4] C. N. Johnson, et al., Biodiversity losses and conservation responses in the Anthropocene. Science 356, 270-275 (2017).

[5] E. F. Lambin, P. Meyfroidt, Global land use change, economic globalization, and the looming land scarcity. Proceedings of the National Academy of Sciences of the United States of America 108, 3465-3472 (2011).

[6] J. Rockström, et al., A safe operating space for humanity. Nature 461, 472-475 (2009).

[7] W. Steffen, et al., Trajectories of the Earth System in the Anthropocene. Proceedings of the National Academy of Sciences of the United States of America 115, 8252-8259 (2018).

[8] Raworth, K. (2017). Doughnut Economics: Seven Ways to Think Like a 21st-Century Economist. Vermont: Chelsea Green Publishing.

[9] R. I. McDonald, Global urbanization: can ecologists identify a sustainable way forward? Frontiers in Ecology and the Environment 6, 99-104 (2008).

[10] N. Bymoen, N. Warner, Maximizing mobility: transportation efficiency and infrastructure development in the urban boundary rural area of Vancouver, Canada. Undergraduate Research and Innovation Conference (2018).

[11] J. Nivala, A. Zehnsdorf, M. van Afferden, R. A. Müller, "Green infrastructure for increased resource efficiency in urban water management" in Urban Transformations: Sustainable Urban Development Through Resource Efficiency, Quality of Life and Resilience, Future City., S. Kabisch, et al., Eds. (Springer International Publishing, 2018), pp. 133-143.

[12] J. R. Burger, et al., The macroecology of sustainability. PLoS Biology 10 (2012).

[13] D. W. O’Neill, A. L. Fanning, W. F. Lamb, J. K. Steinberger, A good life for all within planetary boundaries. Nature Sustainability 1, 88-95 (2018).

[14] Minnesota Pollution Control Agency. 2014 County Level $\mathrm{NO}_{x}$ Emissions. Retrieved from https://www.pca.state.mn.us/air/statewide-and-county-air-emissions.

[15] US Geological Survey. 1987-2006. County-Level Estimates of Nitrogen and Phosphorus from Commercial Fertilizer for the Conterminous United States. Retrieved from 
https://water.usgs.gov/GIS/metadata/usgswrd/XML/sir2012-5207_county_fertilizer. $\mathrm{xml}$.

[16] US Geological Survey. 2015. USGS Water Use Data From Minnesota. Retrieved from https://waterdata.usgs.gov/nwis/wu.

[17] Minnesota Board of Water \& Soil Resources. 2019. Conservation Lands SummaryStatewide. Retrieved from https://bwsr.state.mn.us/sites/default/files/2019-08/CLS_ Statewide_Summary.pdf.

[18] Minnesota Department of Health. 2015. County Level PM 2.5 Air Quality Query. Retrieved from https://data.web.health.state.mn.us/air_query.

[19] Minnesota Department of Health. 2015. County Level O 3 Air Quality Query. Retrieved from https://data.web.health.state.mn.us/air_query.

[20] Feeding America Research. 2017. Overall and Child Food Insecurity by County. Retrieved from https://www.feedingamerica.org/research/map-the-meal-gap/by-county.

[21] National Center for Health Statistics - Mortality Files. 2015-2017. Minnesota Life Expectancy. Retrieved from https://www.countyhealthrankings.org/app/minnesota/2019/ measure/outcomes/147/data.

[22] American Community Survey. 2018. Minnesota Education Data. Retrieved from https://www.towncharts.com/Minnesota/Education/Hennepin-County-MN-Educationdata.html.

[23] US Census Bureau. 2006-2010 American Community Survey 5-Year Estimates Data. 2010. Retrieved from https://factfinder.census.gov/faces/tableservices/jsf/pages/productview.xhtm

[24] Uniform Crime Reporting Program Data. 2010. County-Level Detailed Arrest and Offense Data, United States. Retrieved from https://www.countyhealthrankings.org/app/ minnesota/2013/measure/factors/43/data.

[25] Minnesota Secretary of State, U.S. 2016. Voter Turnout By County.

[26] US Census Bureau. 2010. American Community Survey (ACS), 1-year estimates, table B19083. Retrieved from https://www.livestories.com/statistics/minnesota/gini-indexincome-inequality.

[27] Minnesota Legislature Legislative Coordinating Commission. 2019. House and Senate District Information. Retrieved from https://www.gis.leg.mn/php/house. php?Report=HouseMem.

[28] Wilder Reserarch. 2015. Minnesota Homeless Study. Retrieved from http://mnhomeless.org/minnesota-homeless-study/reports-and-fact-sheets/2015/2015-homeless-ramsey-county-fact-sheet-2-17.pdf.

[29] Connected Nation. 2019. County Broadband Service. Retrieved from https://mn.gov/ deed/assets/county-bb-service-availability_tcm1045-255846.pdf.

[30] Minnesota Pollution Control Agency. 2017. Report on 2017 SCORE Programs. Retrieved from https://www.pca.state.mn.us/waste/report-2017-score-programs.

[31] Minnesota Department of Health. 2017. Drinking Water Query. Retrieved from https://data.web.health.state.mn.us/drinkingwater_query.

[32] C. A. Lepczyk, et al., Biodiversity in the city: fundamental questions for understanding the ecology of urban green spaces for biodiversity conservation. BioScience 67, 799-807 (2017).

[33] E. Huddart-Kennedy, T. M. Beckley, B. L. McFarlane, S. Nadeau, Rural-urban differences in environmental concern in Canada. Rural Sociology 74, 309-329 (2009). 
[34] J. F. Kenny, et al., Estimated use of water in the United States in 2005 (U.S. Geological Survey, 2009).

[35] J. T. Lehman, D. W. Bell, K. E. McDonald, Reduced river phosphorus following implementation of a lawn fertilizer ordinance. Lake and Reservoir Management 25, 307-312 (2009).

[36] R. W. Portmann, J. S. Daniel, A. R. Ravishankara, Stratospheric ozone depletion due to nitrous oxide: influences of other gases. Philosophical Transactions of the Royal Society of London. Series B Biological Sciences 367, 1256-1264 (2012).

[37] L. Seeliger, I. Turok, Towards sustainable cities: extending resilience with insights from vulnerability and transition theory. Sustainability 5, 2108-2128 (2013).

[38] A. Golub, K. Martens, Using principles of justice to assess the modal equity of regional transportation plans. Journal of Transport Geography 41, 10-20 (2014).

[39] D. Martin, H. Jordan, P. Roderick, Taking the bus: incorporating public transport timetable data into health care accessibility modelling. Environment and Planning A 40, 2510-2525 (2008).

[40] N. Paulley, et al., The demand for public transport: the effects of fares, quality of service, income and car ownership. Transport Policy 13, 295-306 (2006). 